\title{
STUDY OF GROUND PORK THAWING DYNAMICS USING MAGNETIC RESONANCE IMAGING
}

Vladimir M. Stefanovskiy' ${ }^{1 \star}$, Evgeny V. Morozov², Vyacheslav M. Bouznil ${ }^{3}$

${ }^{1}$ All-Russian Scientific Research Institute of Refrigeration Industry - Branch of V.M. Gorbatov Federal Research Center for Food Systems of RAS, Moscow, Russia

${ }^{2}$ Institute of Chemistry and Chemical Technology of the Siberian Branch of the Russian Academy of Science Branch of Federal Research Center "KSC SB RAS”, Krasnoyarsk, Russia

${ }^{3}$ All-Russian Scientific Research Institute of Aviation Materials of the state research center of the Russian Federation, Moscow, Russia

Keywords: thawing, ground pork, research method, magnetic resonance imaging

\begin{abstract}
Visualization of changes in shape and size of the frozen residue during the thawing of ground pork is implemented using magnetic resonance imaging. A technique has been developed to study the displacement of thawing front line without damage to integrity of the object being thawed. It has been established that the melting of bound water crystals outran the melting of free water crystals in meat. A mathematical model that adequately describes the experimental data obtained in the analysis of tomograms is proposed. Tomograms are an important information source for studying the patterns of heat and mass transfer during the thawing of frozen foods.
\end{abstract}

\section{Introduction}

Monitoring of continuous refrigeration chains indicates that transportation of frozen goods with numerous handling operations or emergencies causes partial (and sometimes complete) thawing of frozen products. Subsequent refreezing changes the structure-forming and water-holding properties, increases losses during thawing and reduces sensory quality of the thawed products. For effective control of these changes, it is necessary to conduct a system analysis of food thawing dynamics.

Traditionally, the rate of melting is defined as the ratio of thawing front line distance to the time. Monitoring of the phase boundary displacement may be achieved by using modern methods of internal imaging, such as optical coherence tomography, ultrasound imaging, X-ray computer tomography, magnetic resonance imaging (MRI), thermal imaging methods providing real-time information about the processes in the system [1]. Among these, MRI method is one of the most common and effective. MRI has proven itself both in medical diagnostics due to its non-invasiveness, safety and high informativity [2] and in food system studies including the impact of freezing and thawing on the quality of meat, fish and vegetable products $[3,4,5,6,7,8]$.

The purpose of the work is to test the method of MRI imaging to assess the degree of thawing of minced meat, to identify the characteristics of the course of this process and to offer a method for calculating the thickness of the thawed layer.

\section{Materials and methods}

"Ideal product" model was used as a test subject for MRI studies, which was originally proposed in literature [9] in the form of a plastic cylindrical container filled with glass balls $(\mathrm{d}=1 \mathrm{~mm})$ and water. Container volume is 1.8 $\mathrm{ml}$. The weight of the model sample contents was $4.37 \mathrm{~g}$ (the mass fraction of water was $22.9 \%$ ). A small amount of a paramagnetic substance containing gadolinium ions (paramagnetic contrast agent gadodiamide) was added to the water, the concentration of which did not exceed 20 ppm. This made it possible to significantly reduce the time of nuclear magnetic relaxation of water and increase the efficiency of the applied MRI techniques through the use of much shorter pulse sequences.

In the second stage of the study, the container was filled with ground pork. Ground meat weight was $1.67 \mathrm{~g}$.

The samples were placed in a tomographic scanner sensor, frozen with nitrogen gas at a temperature of minus $30{ }^{\circ} \mathrm{C}$ and a speed of 0.15 to $0.25 \mathrm{~m} / \mathrm{s}$. Thawing was carried out with an air at room temperature $\left(20^{\circ} \mathrm{C}\right)$ at the same speed range. After a specified time, the current tomographic image was recorded.

Tomographic measurements were carried out in the Krasnoyarsk regional center for collective use using Bruker AVANCE DPX 200 NMR micro-tomographic scanner in the following configuration: shielded vertical superconducting magnet with an aperture of $89 \mathrm{~mm}$ and a magnetic field of $4.7 \mathrm{~T}$; PH Micro 2.5 tomographic sensor with GREATE 3/40 amplifiers; water-cooled gradient 
system with a maximum gradient of $1 \mathrm{~T} / \mathrm{m}$; a bird cage type radio-frequency coil with a diameter of $25 \mathrm{~mm}$ set to a proton resonance frequency of $200 \mathrm{MHz}$; Paravision 4.0 software. All tomograms were recorded by $1 \mathrm{H}$ nucleus. To obtain tomograms, we used spin echo based technique (Multi Slice Multi Echo [10]) with TR/TE parameters of $100 / 3 \mathrm{~ms}$, field of view of $40 \mathrm{~mm}$, matrix of $128 \times 128$ pixels, slice thickness of $1 \mathrm{~mm}$, and time to obtain an individual image of $25 \mathrm{~s}$.

\section{Presults and discussion}

MRI during the thawing of test subject showed that at the initial stage of sample heating, ice areas have almost no signal and are represented in tomograms by black color (Figure 1, image A, images B,C,D - demonstrate an increase in the thickness of the thawed layer in the form of a light area). Water droplet forming during the thawing process leads to the visualization of bright areas at the sample perimeter. As melting proceeds, the frozen part area gradually decreases until the ice melts completely.

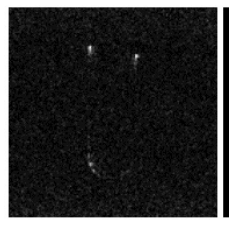

A

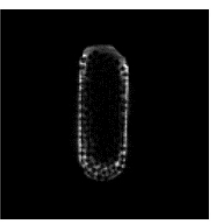

B

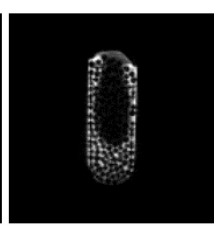

C

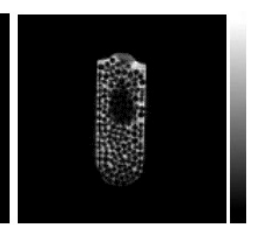

D
Figure 1. A series of model sample MRI images during thawing

The phase boundary may be visualized more clearly by a series of differential images when subtracting successive tomograms. Only the line of signal change will remain on the images, i.e. the desired phase transition front line (Figure 2).
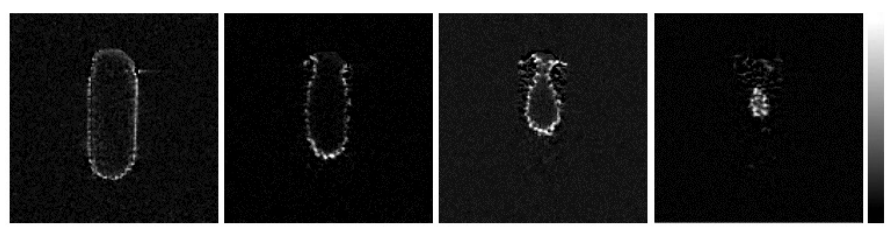

Figure 2. A series of model sample differential images during thawing

Tomograms reveal the characteristics of the shape change of the sample frozen part, the geometry of which differs from the original geometry of the frozen sample (cylinder). This phenomenon will be the subject of further research.

The developed visualization method allows not only to study the dynamics of ice melting in a model sample, but also to identify the characteristics of meat and meat products thawing. Also using mathematical methods of image processing, it is possible to quantify the volume of the frozen part and its dynamics during thawing.

Our observations of the ground meat thawing showed that at the initial stage, the signal intensity gradually increases almost in all parts of the sample. This may be explained by the fact that in addition to water molecules, a large number of proton-containing molecules (proteins, fats, carbohydrates) are present in meat, which contribute to overall signal intensity in the image, even for a frozen object. While water molecules in ice are considered to be non-labile, biological molecules retain some lability due to the segmentation movement of biopolymer chains.

It is well known that water in biological tissues is represented in various states including free and bound ones with varying degrees of binding. [11]. Thus, water molecules in a gel-like state (water in collagen macrostructure and other tissues) also retain sufficient lability at negative temperatures, unlike water molecules in the structure of ice. This leads to the conclusion that during thawing of ground meat, a gradual increase in the signal intensity is observed throughout the sample due to increase in the local dynamics of bound water molecules and improvement in the dynamics of the segmentation movement of biopolymer chains.

Consequently, when the conditions for melting of ice microcrystals (free water between the meat structural elements) are achieved, the target front line may be visualized only by differential images (Figure 3, the differential images are presented in color for greater clarity).
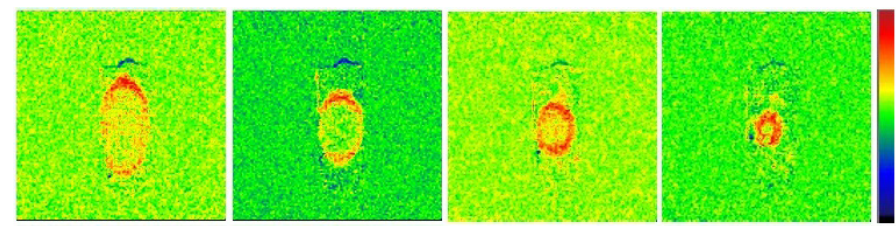

Figure 3.A series of the ground meat sample differential images during thawing

The analysis of tomograms shows that the frozen part of the sample (of a small size) is quickly heated to a cryoscopic temperature, while the moving interface between the frozen and unfrozen areas remains until the end of melting.

Another important aspect of the problem under study is a quantitative assessment of the thawing dynamics. The solution of this problem is associated with the construction and analysis of a mathematical model for the process. Frozen object thawing is mathematically formulated as follows [12]:

$$
\begin{aligned}
& \frac{\partial t_{1}(x, \tau)}{\partial \tau}=a_{1} \frac{\partial^{2} t_{1}(x, \tau)}{\partial x^{2}} \quad(\tau>0 ; 0<x<\xi) \\
& \frac{\partial t_{2}(x, \tau)}{\partial \tau}=a_{2} \frac{\partial^{2} t_{2}(x, \tau)}{\partial x^{2}} \quad(\tau>0 ; \xi<x<\infty) \\
& t_{2}(x, 0)=f(x) \\
& t_{1}(0, \tau)=\varphi(\tau) \\
& t_{1}(\xi, \tau)=t_{2}(\xi, \tau)=t_{3}=\text { const. } \\
& \frac{\partial t_{2}(\infty, \tau)}{\partial x}=0
\end{aligned}
$$


At the phase boundary

$$
-\lambda_{1} \frac{\partial t_{1}(\xi, \tau)}{\partial x}+\lambda_{2} \frac{\partial t_{2}(\xi, \tau)}{\partial x}=r \rho_{2} \frac{\partial \xi}{\partial \tau}
$$

where index of 1 refers to the thawed layer with a thickness of $\xi$; index of 2 refers to the frozen part of the object; $\lambda$ is the coefficient of thermal conductivity, $\mathrm{W} /(\mathrm{m} \mathrm{K})$; $r$ is the specific heat of thawing, $\mathrm{J} / \mathrm{kg} ; \rho$ is the density, $\mathrm{kg} / \mathrm{m} 3$; $\mathrm{t} \mathrm{t} 3$ is the cryoscopic temperature, ${ }^{\circ} \mathrm{C}$; $\tau$ is the time, $s$.

The problem of heat transfer by heat conduction as an example of conjugation of two temperature fields of the frozen and thawed object areas upon special conditions on the moving phase boundary was solved for the first time in 1831 by the members of the Russian Academy of Sciences, Prof. Lame and Prof. Clapeyron, and later in 1889 by the mathematician from Vienna, Stefan [12]. The differential equation expressing the relationship between the thickness of the thawed layer $\xi$ and the thawing time $\tau$ is as follows:

$r \rho_{2} \frac{d \xi}{d \tau}=\frac{\lambda_{1}\left(t_{c}-t_{3}\right)}{b+\sqrt{\pi a_{1} \tau} \operatorname{erf} \frac{\xi}{2 \sqrt{a_{1} \tau}}} \exp \left(-\frac{\xi^{2}}{4 a_{1} \tau}\right)-\frac{\lambda_{2}\left(t_{3}-t_{4}\right)}{\sqrt{\pi a_{2} \tau} \operatorname{erfc} \frac{\xi}{2 \sqrt{a_{2} \tau}}} \exp \left(-\frac{\xi^{2}}{4 a_{2} \tau}\right)$

where $\quad b=\lambda_{1}\left(1 / \alpha^{+} \delta_{i i} / \lambda_{i j}\right) \quad$ is the coefficient of thermal resistance at the boundary of the thawed layer and the container wall; $\alpha$ is the coefficient of heat transfer from air to the container; $\delta \mathrm{cт}$ and $\lambda_{\mathrm{c} \text { T }}$ are the thickness and the thermal conductivity of the container wall.

For ground meat at cryoscopic temperature and heat transfer in the boundary conditions of the third kind, the equation (8) has the following form:

$$
r \rho_{2} \frac{d \xi}{d \tau}=\frac{\lambda_{1}\left(t_{c}-t_{3}\right)}{b+\sqrt{\pi a_{1} \tau} \operatorname{erf} \frac{\xi}{2 \sqrt{a_{1} \tau}}} \exp \left(-\frac{\xi^{2}}{4 a_{1} \tau}\right)
$$

By decomposing exp and erf functions into series in (9) and limiting them to the first members, the following relation is obtained:

$$
\tau=\frac{r \rho_{2}}{\lambda_{1}\left(t_{c}-t_{3}\right)}\left(\frac{\xi^{2}}{2}+b \xi\right)
$$

Due to certain assumptions when obtaining a private relationship (10), it is appropriate to verify the adequacy of this mathematical model. When performing calculations, the thermophysical characteristics of meat are taken from $[13,14,15,16]: \mathrm{r}=130,000 \mathrm{~J} / \mathrm{kg} ; \rho 2=964 \mathrm{~kg} / \mathrm{m} 3 ; \lambda 1=0.45$ $\mathrm{W} /(\mathrm{m} \mathrm{K})$; defrosting environment $\mathrm{tc}=20^{\circ} \mathrm{C}$; $\mathrm{t} 3=-1^{\circ} \mathrm{C}$; $\alpha=10 \mathrm{~W} /\left(\mathrm{m} 2{ }^{\circ} \mathrm{K}\right) ; \delta \mathrm{cT}=0.0001 \mathrm{~m} ; \lambda \mathrm{cT}=0.2 \mathrm{~W} /(\mathrm{m} \mathrm{K})$.

Figure 4 presents the comparison of experimental data with a theoretical solution (10).

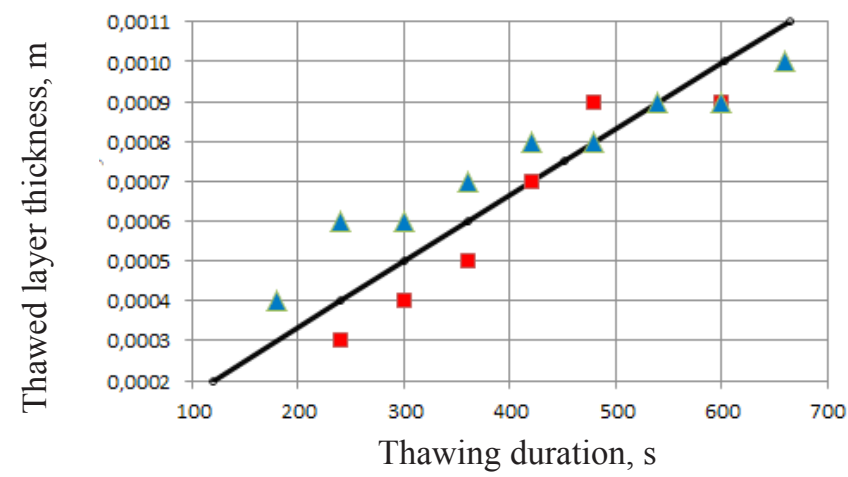

Comparison of the results obtained by analytical and experimental methods indicates the possibility of a dialogue with computer, i.e. to analyze alternatives, verify hypotheses, carry out experiments with mathematical models significantly increasing the efficiency of engineering development in creating fundamentally new refrigeration technologies and systems.

\section{Conclusions}

The visualization of the thawing boundary displacement in a frozen object indicates that magnetic resonance imaging may be used in the industry to determine the degree of meat product thawing in the case of violation of the refrigeration chain continuity.

Comparison of the results obtained by calculation and experimental method proves the validity of the theoretical equations and the possibility of their use in the computer simulation of thawing processes.

A series of tomograms over time is not only a source of information, but also a tool for monitoring the process of industrial thawing of frozen products.

\section{REFERENCES}

1. Xiong, Z., Sun, D.W., Pu, H., Gao, W., Dai, Q. (2015). Applications of emerging imaging techniques for meat quality and safety detection and evaluation: A review. Critical Reviews in Food Science and Nutrition, 57(4), 755-768. DOI: 10.1080/10408398.2014.954282 2. Liney, G. P. (2006). MRI in clinical practice. London:SpringerVerlag. -128 p. ISBN 978-1-84628-161-7

3. Ebrahimnejad, H., Ebrahimnejad, H., Salajegheh, A., Barghi, H. (2018). Use of magnetic resonance imaging in food quality control: A review. Journal of Biomedical Physics and Engineering, 8(1), 127132. DOI: $10.22086 /$ jbpe.v0i0.628

4. Evans, S.D., Nott, K.P., Kshirsagar, A.A., Hall, L.D. (1998). The effect of freezing and thawing on the magnetic resonance imaging parameters of water in beef, lamb and pork meat. International Journal of Food Science and Technology, 33(3), 317-328. DOI: 10.1046/j.1365-2621.1998.00165.x
5. Kerr, W.L., Kauten, R.J., McCarthy, M.J., Reid, D.S. (1998) Monitoring the Formation of Ice During Food Freezing by Magnetic Resonance Imaging. LWT - Food Science and Technology, 31(3), 215-220. DOI:10.1006/fstl.1997.0323

6. Nott, K.P., Evans, S.D., Hall, L.D. (1999). The Effect of FreezeThawing on the Magnetic Resonance Imaging Parameters of Cod and Mackerel. LWT - Food Science and Technology, 32(5), 261-268. DOI: 10.1006/fstl.1999.0549

7. Hills, B.P., Goncalves, O., Harrison, M., Godward, J. (1997). Real Time Investigation of the Freezing of Raw Potato by NMR Microimaging. Magnetic Resonance in Chemistry, 35, 829-836.

8. Frelka, J.C., Phinney, D.M., Yang, X., Knopp, M.V., Heldman, D.R., Wick, M.P., Vodovotz, Y. (2018). Assessment of chicken breast meat quality after freeze/thaw abuse using magnetic resonance imaging techniques. Journal of Science Food and Agriculture, 
99(2), 844-853. D0I:10.1002/jsfa.9254

9. Stefanovskiy, V.M., Polyakov, I.A., Petrov, V.V. (2016). Research of moisture migration during partial freezing of ground beef. Theory and practice of meat processing, 1(4), 43-50. (In Russ.) DOI: 10.21323/2414-438X-2016-1-4-43-50

10. Bernstein, M.A., King, K.F., Zhou, X.J. (2004). Handbook of MRI Pulse Sequences. Burlington: Elsevier Academic Press. -1049 p. ISBN: 9780120928613

11. G. Kerch. Distribution of tightly and loosely bound water in biological macromolecules and age-related diseases. International Journal of Biological Macromolecules 118 (2018) 1310-1318)

12. Lykov, A.V. (1968). Theory of heat conduction. M: Higher
School. - 559 p.

13. Ginsburg, A.S., Gromov, G.l., Krasovskaya, V.S., Ukolov, M.A.(1975). Thermophysical characteristics of food products and materials. Reference book M: Food industry. -223 p.

14. Almashi, E., Erdeli, L., Sharoy, T. (1981). Rapid freezing of foods (translated from Hungarian). M: Light and food industry .-408 p.

15. Chubik, I.A., Maslov, A.M. (1970). Handbook on the thermophysical characteristics of food products and semi-finished products. M: Food industry .-184 p.

16. Refrigeration equipment. Encyclopedic reference (book 2). M: Gostorgizdat. 1961. -575 p.

\section{AUTHOR INFORMATION}

Vladimir M. Stefanovskiy - doctor of technical sciences, professor, head scientific collaborator, All-Russian Scientific Research Institute of Refrigeration Industry - Branch of V.M. Gorbatov Federal Research Center for Food Systems of RAS. 125422, Moscow, Kostyakova str., 12. Tel.: +7-495-253-15-74. E-mail: stef-vm@yandex.ru *corresponding author

Evgeny V. Morozov - candidate of physical and mathematical cciences, senior researcher, Institute of Chemistry and Chemical Technology of the Siberian Branch of the Russian Academy of Sciences - Branch of Federal Research Center "KSC SB RAS". 660036, Krasnoyarsk, Akademgorodok 50/24. Tel.: +7-391-249-85-61. E-mail: morozov_if@mail.ru

Vyacheslav M. Bouznik - doctor of chemical sciences, professor, academician of RAS, advisor to the general director, All-Russian Scientific Research Institute of Aviation Materials of the state research center of the Russian Federation. 105005, Moscow, Radio str., 17. Teл.: +7-977-969-70-30 E-mail:bouznik@ngs.ru

Contribution

Authors equally contributed to the writing of the manuscript and are equally responsible for plagiarism

The authors declare no conflict of interest

Conflict of interest

Received 04.12.2018

Accepted in revised 20.01.2019

Accepted for publication 01.03.2019 